REVISTA ANDALUZA DE ANTROPOLOGÍA

NÚMERO 15: ACTIVIDADES TURÍSTICAS, CIUDAD Y PATRIMONIO CULTURAL: MIRADAS CRÍTICAS. TOURIST ACTIVITIES, CITY AND CULTURAL HERITAGE: CRITICAL GLANCES SEPTIEMBRE DE 2018

ISSN 2174-6796

[pp. 211-215]

http://dx.doi.org/10.12795/RAA.2018.15.10

\title{
BRAZZABENI, MICOL, CUNHA, MANUELA IVONE y FOTTA, MARTIN, eds. (2016). Gypsy Economy, Romani Livelihoods and Notions of Worth in the 21st Century. New York: Berghahn Books, 272 pp.
}

\author{
Clara Chinoy \\ Doctorando en Antropología, Universidad de Sevilla
}

El libro Gypsy Economy, Romani Livelihoods and Notions of Worth in the 21st Century es el volumen 3 de la serie The Human Economy, (Berghahn Books 2016), orientado a "examinar cómo los intereses humanos se expresan en nuestro mundo desigual a través de actividades económicas y aspiraciones concretas." (contraportada) Aprovechando la gran variedad de respuestas de los Roma, o Gypsies, respecto a los diferentes contextos históricos, económicos y sociales de distintos países con el fin de examinar tipos de actividad económica al margen de los sistemas económicos establecidos y los mercados dominantes, los autores reflexionan sobre las maneras en las que las personas se sitúan en relación con el mercado, los cambiantes papeles del estado en el mercado y las finanzas y sus propias situaciones históricas.

Enmarcados por una extensa base teorética en el contexto de los "Gypsy Studies" en la introducción, escrita por los editores Micol Brazzabeni, Manuela Ivone Cunha y Martin Fotta, y una conclusión de Keith Hart que resalta la importancia del trabajo etnográfico en el mundo global actual, los capítulos del libro son el resultado de las discusiones de un taller organizado la European Science Foundation (ESF), el Centre for Research 
in Anthropology (CRIA) y el Lisbon University Institute (LUI) en 2012. Los capítulos se presentan como basan en breves estudios etnográficos, realizados en las últimas tres décadas. Planteando descripciones y analysis sobre las prácticas económicas de una variedad de grupos, desde Slovakia, Hungría y Romanía en el antiguo bloque soviético, hasta Italia, España y Portugal en el oeste de Europa, y Brasil al otro lado del Atlántico. Presentan una diversidad de prácticas y se basan en una variedad de perspectivas teóricas, todo con la intención de representar los parámetros de los Gitanos mismos en una variedad de contextos sociales y económicos locales “...cómo por ejemplo, diferentes actividades son definidas y fabricadas por los Gitanos, cómo los llaman y cómo vienen con sus criterios específicos de éxito." (p.16), Así pretenden explorar cómo se influyen mutuamente estrategias económicas y relaciones sociales, posicionando esta actividad en el contexto de cambios en las economías y mercados mayoritarios.

Tomas Hrustic y Judith Durst exploran cómo las relaciones sociales se establecen a través del intercambio de dinero o situación económica en vez de la antigua y compleja moralidad personal que tradicionalmente regía; las redes de parentesco ya no sirven para cubrir todas las necesidades económicas. El capítulo de Hrustic es más descriptivo, observando la práctica de Roma en un campamento en Slovakia de acudir a usureros en su propia comunidad, y la manera en que los mismos Roma perciben esta práctica, que ha creado un ciclo de dependencia que penetra todo el sistema social, incluso de parentesco, en un cambio significativo respecto al modelo tradicional de reciprocidad y solidaridad. (p.34) Durst ofrece una perspectiva más amplia y teórica en su investigación en relación a la forma en que la política local de un pueblo de Hungría se basa en la distribución o redistribución de dinero en una comunidad donde las relaciones "patróncliente" que regía entre Roma y no Roma durante la época socialista ha cambiado a una situación en la que la deuda es el tipo dominante de conexión social entre los gitanos mismos. Entre los dos grupos la práctica del préstamo informal les parece una respuesta lógica a su situación económica - incluso a veces cambian de papel, acortando la distancia entre los distintos roles $-\mathrm{y}$ reconocen que es una manera de salir del ciclo de pobreza. En el campamento de Slovakia identifican la falta de capacidad de manejar el dinero -resultando en pobreza- como una característica étnica de los Roma, y se valora el éxito de los usureros con comparación con los "diline Roma" (Gitanos tontos) que son sus clientes. En Hungría el juicio moral surge contra aquel que no obedece las formas establecidas de combinar solidaridad con beneficios personales.

Sara Sama Acedo y Jan Grill reflexionan sobre estrategias que combinan movilidad con identidad local. Aplicando el concepto de "interstices" y teorías de grupos parapatéticos y nichos económicos, Sama describe cómo unos tratantes de ganado, una minoría pobre entre los Ciganos portugueses, se mueven entre un "hogar" más o menos permanente, y 
campamentos de nómadas con su doble significado como itinerante, por unlado, y marginal y delincuente por otro, creados por el gobierno en la transición entre una economía rural de agricultura y la mecanización y desarrollo urbano que empezó en los años ‘ 50 . Territorialidad, semi-permanencia y movilidad no se perciben como contradictorios, sino responden a relaciones intra-étnicas y cambiante políticas cambiantes. Grill se enfoca en la combinación de dos modalidades económicas entre Roma eslovacos en la transición del socialismo al post-socialismo y migración internacional: el "honesto" pero duro trabajo físico disponible en el Reino Unido, donde empezaron a migrar después de la entrada de Eslovaquia en la Unión Europea en 2004, y las prácticas más precarias, marginales y semi-legales o ilegales, pero a la vez lucrativas, de "arreglar dinero" ("fixing up money") aprovechando ayudas sociales y/o oportunidades de negocio a su vuelta a Eslovaquia.

Marco Solimene considera la territorialidad y la manipulación de imágenes estereotipadas de los Roma y relaciones con la sociedad mayoritaria de chatarreros de origen bosnio en la ciudad de Roma. Explora las implicaciones simbólicas de los conceptos de baxt (suerte o intervención divina) y soró, astucia, en la construcción de identidad. Gergö Pulay destaca la frase "soy bueno, pero también loco" en la economía "de la calle" en un barrio pobre e infame - pero no únicamente Roma - al sur de Bucharest. La locura sugiere la capacidad de perder control y convertirse en salvaje; la necesidad de no dejar que nadie le tome a uno como tonto o no ser capaz de defenderse recuerda el uso del término "bad" (malo) en la construcción de identidad en la comunidad africano-americana en los Estados Unidos.

Reflexionando sobre estrategias económicas de los Roma en Transilvania, Martin Olivera habla del "Rom work" hecho por hombres, fuera del ámbito de la subsistencia doméstica, generalmente en contacto con los no-Roma. No solo crea un superávit de ingresos generalmente gastado enseguida - sino que "Rom work" demuestra las calidades de éxito de un hombre Rom, relacionado con el concepto de "baxt" o suerte considerado por Solimene. No es el trabajo en sí, sino la capacidad de establecer buenas relaciones con clientes no-Roma y ganar dinero de la sociedad mayoritaria, lo que permite a cada la independencia de hacer su trabajo mientras gana buen dinero, manteniendo así su sitio en su propia comunidad.

El éxito de las mujeres Calin en las afueras de Sao Paolo en leer las manos de la gente no-Roma descrito por Florencia Ferrari también se basa en el establecimiento de una relación entre dos personas y la manipulación de esta relación y los estereotipos que 
tiene la gente de los Roma. Martín Fotta examina la manera en la que los conceptos de vergüenza, honor y fuerza, o la capacidad de controlar su entorno con intercambios de dinero y favores, genera estabilidad y resistencia entre los Calon de Bahía, Brasil.

En dos capítulos que se salen un poco del propósito presentado en la introducción, Catalina Tesar explora cómo la constante construcción y re-construcción de casas de los Roma en Rumanía refleja el desarrollo de grupos domésticos y a la vez simboliza la mejoría de su situación económica y social, mientras Nathalie Manrique explora la idea de generosidad en el desarrollo de relaciones dentro de la comunidad gitana y con la sociedad mayoritaria.

Los textos en Gypsy Economy reconocen la gran diversidad de los Roma y la relación entre estas diferencias y las situaciones históricas y locales de cada grupo. Además, la mayoría de los autores procuran utilizar el lenguaje de los Roma para hablar de sus actividades económicas, a pesar de dificultades de traducción de variedades de Romanés o idiomas locales al inglés del libro. Esta iniciativa de ver e intentar describir las estrategias de los Roma en sus propios términos es un paso importante hacia corregir las tendencias esencialistas - "todos son así" - o constructivista- "no existen como etnicidad" - y la visión por un lado romántica y por otro despectiva que ha caracterizado los estudios de los Roma durante largo tiempo.

Las estrategias económicas de los Roma han sido claves en su supervivencia a lo largo de los siglos, y se suele examinar como un elemento más en estos estudios. El propósito comparativo de libro Gypsy Economy va más allá. A través de detalles locales los autores examinan distinciones entre agencia y suerte, cuestiones de moralidad, honor, vergüenza y respecto, sociabilidad, comunidad, jerarquía y relación con la sociedad mayoritaria para sugerir elementos de la construcción de Romanipen, gitaneidad o identidad gitana, a través del "performance" de estas actividades en diferentes contextos. Muestra la preferencia de los Roma, descrita por muchos antropólogos, (Okeley, Stewart, Piasere, Guy y Blasco y más) por trabajos que se basan en movilidad, independencia, negociación, en vez de trabajo regular asalariado - trabajos descritos de varias maneras como "marginales" intersticiales" o "informales," y demuestra la importancia de relaciones personales, combinación de estrategias o actividades, viejas y nuevas oportunidades, y maneras de aprovechar apoyo estatal. De ahí surge la imagen de un mundo donde las contradicciones - sobre todo entre movilidad/estabilidad o asentamiento/territorialidad y legalidad/ilegalidad/semi-legalidad - y precariedad son la norma. Más que las actividades en sí, parece que la aceptación de esta precariedad y contradicciones y la combinación de suerte y astucia con que se enfrentan a ello, define el éxito y de ahí la definición de Romanipen. 
El propósito del libro va más allá del interés específico por entender a los Roma, al sugerir la relevancia de sus respuestas económicas para nuestro mundo actual. Como comenta Keith Hart en su "Afterword," “...la etnografía antropológica es diferente en que traemos por lo menos la aspiración de generalizar sobre la condición humana total o situar nuestras conclusiones en el marco más amplio de comparación" (p. 241). Parece que las respuestas flexibles y creativas a sus circunstancias por parte de los diversos grupos de Roma se hacen cada vez más relevantes en el mundo "globalizado" e incierto del momento histórico en que vivimos. Iluminando el mundo de economías "alternativas" "intersticiales" o "marginales" y su relación con el mercado y la economía mayoritaria este análisis de las estrategias económicas de los Roma resulta muy relevante más allá de nuestro interés por entender los Roma en sí, y así da un buen paso hacía cumplir con esta aspiración de la etnografía antropológica, y además destacar la relevancia de esta minoría más allá de su interés como una comunidad percibida como diferente y exótica. 